\title{
Multivalued fixed point theorems in cone $b$-metric spaces
}

\author{
Akbar Azam ${ }^{1}$, Nayyar Mehmood ${ }^{1}$, Jamshaid Ahmad ${ }^{1 *}$ and Stojan Radenović ${ }^{2}$
}

"Correspondence:

jamshaid_jasim@yahoo.com

${ }^{1}$ Department of Mathematics, COMSATS Institute of Information

Technology, Chak Shahzad, Islamabad, 44000, Pakistan

Full list of author information is available at the end of the article

\begin{abstract}
In this paper we extend the Banach contraction for multivalued mappings in a cone $b$-metric space without the assumption of normality on cones and generalize some attractive results in literature.
\end{abstract}

MSC: $47 \mathrm{H} 10 ; 54 \mathrm{H} 25$

Keywords: cone b-metric space; non-normal cones; multivalued contraction; fixed points

\section{Introduction}

The analysis on existence of linear and nonlinear operators was developed after the Banach contraction theorem [1] presented in 1922. Many generalizations are available with applications in the literature [2-13]. Nadler [14] gave its set-valued form in his classical paper in 1969 on multivalued contractions. A real generalization of Nadler's theorem was presented by Mizoguchi and Takahashi [15] as follows.

Theorem 1.1 [15] Let $(X, d)$ be a complete metric space and let $T: X \rightarrow 2^{X}$ be a multivalued map such that $T x$ is a closed bounded subset of $X$ for all $x \in X$. If there exists a function $\varphi:(0, \infty) \rightarrow[0,1)$ such that $\lim _{r \rightarrow t^{+}} \sup \varphi(r)<1$ for all $t \in[0, \infty)$ and if

$$
H(T x, T y) \leq \varphi(d(x, y))(d(x, y)) \quad \text { for all } x, y \in X,
$$

then $T$ has a fixed point in $X$.

Huang and Zhang [10] introduced a cone metric space with normal cone as a generalization of a metric space. Rezapour and Hamlbarani [16] presented the results of [10] for the case of a cone metric space without normality in cone. Many authors worked on it (see [17]). Cho and Bae [18] presented the result of [15] for multivalued mappings in cone metric spaces with normal cone.

Recently Hussain and Shah [19] introduced the notion of cone $b$-metric spaces as a generalization of $b$-metric and cone metric spaces. In [20] the authors presented some fixed point results in cone $b$-metric spaces without assumption of normality on cone.

In this article we present the generalized form of Cho and Bae [18] for the case of cone $b$-metric spaces without normality on cone. We also give an example to support our main theorem.

O2013 Azam et al.; licensee Springer. This is an Open Access article distributed under the terms of the Creative Commons Attribution License (http://creativecommons.org/licenses/by/2.0), which permits unrestricted use, distribution, and reproduction in any medium, provided the original work is properly cited. 


\section{Preliminaries}

Let $\mathbb{E}$ be a real Banach space and $P$ be a subset of $\mathbb{E}$. By $\theta$ we denote the zero element of $\mathbb{E}$ and by int $P$ the interior of $P$. The subset $P$ is called a cone if and only if:

(i) $P$ is closed, nonempty, and $P=\{\theta\}$;

(ii) $a, b \in \mathbb{R}, a, b \geq 0, x, y \in P \Rightarrow a x+b y \in P$;

(iii) $P \cap(-P)=\{\theta\}$.

For a given cone $P \subseteq \mathbb{E}$, we define a partial ordering $\preceq$ with respect to $P$ by $x \preceq y$ if and only if $y-x \in P ; x \prec y$ will stand for $x \preceq y$ and $x \neq y$, while $x \ll y$ will stand for $y-x \in \operatorname{int} P$, where int $P$ denotes the interior of $P$. The cone $P$ is said to be solid if it has a nonempty interior.

Definition 2.1 [19] Let $X$ be a nonempty set and $r \geq 1$ be a given real number. A function $d: X \times X \rightarrow \mathbb{E}$ is said to be a cone $b$-metric if the following conditions hold:

(C1) $\theta \preceq d(x, y)$ for all $x, y \in X$ and $d(x, y)=\theta$ if and only if $x=y$;

(C2) $d(x, y)=d(y, x)$ for all $x, y \in X$;

(C3) $d(x, z) \preceq r[d(x, y)+d(y, z)]$ for all $x, y, z \in X$.

The pair $(X, d)$ is then called a cone $b$-metric space.

Example 2.1 [20] Let $X=l^{p}$ with $0<p<1$, where $l^{p}=\left\{\left\{x_{n}\right\} \subset \mathbb{R}: \sum_{n=1}^{+\infty}\left|x_{n}\right|^{p}<\infty\right\}$. Let $d: X \times X \rightarrow \mathbb{R}$ be defined as

$$
d(x, y)=\left(\sum_{n=1}^{+\infty}\left|x_{n}-y_{n}\right|^{p}\right)^{\frac{1}{p}},
$$

where $x=\left\{x_{n}\right\}, y=\left\{y_{n}\right\} \in l^{p}$. Then $(X, d)$ is a $b$-metric space. Put $E=l^{1}, P=\left\{\left\{x_{n}\right\} \in E\right.$ : $x_{n} \geq 0$ for all $\left.n \geq 1\right\}$. Letting the map $d^{\prime}: X \times X \rightarrow E$ be defined by $d^{\prime}(x, y)=\left\{\frac{d(x, y)}{2^{n}}\right\}_{n \geq 1}$, we conclude that $\left(X, d^{\prime}\right)$ is a cone $b$-metric space with the coefficient $r=2^{\frac{1}{p}}>1$, but is not a cone metric space.

Example 2.2 [20] Let $X=\{1,2,3,4\}, E=\mathbb{R}^{2}, P=\{(x, y) \in E: x \geq 0, y \geq 0\}$. Define $d: X \times$ $X \rightarrow E$ by

$$
d(x, y)= \begin{cases}\left(|x-y|^{-1},|x-y|^{-1}\right) & \text { if } x \neq y \\ \theta & \text { if } x=y .\end{cases}
$$

Then $(X, d)$ is a cone $b$-metric space with coefficient $r=\frac{6}{5}$. But it is not a cone metric space, because

$$
\begin{aligned}
& d(1,2)>d(1,4)+d(4,2), \\
& d(3,4)>d(3,1)+d(1,4) .
\end{aligned}
$$

Remark 2.1 [19] The class of cone $b$-metric spaces is larger than the class of cone metric spaces since any cone metric space must be a cone metric $b$-metric space. Therefore, it is obvious that cone $b$-metric spaces generalize $b$-metric spaces and cone metric spaces.

Definition 2.2 [19] Let $(X, d)$ be a cone $b$-metric space, $x \in X$, let $\left\{x_{n}\right\}$ be a sequence in $X$. Then 
(i) $\left\{x_{n}\right\}$ converges to $x$ whenever for every $c \in \mathbb{E}$ with $\theta \ll c$ there is a natural number $n_{0}$ such that $d\left(x_{n}, x\right) \ll c$ for all $n \geq n_{0}$. We denote this by $\lim _{n \rightarrow \infty} x_{n}=x$;

(ii) $\left\{x_{n}\right\}$ is a Cauchy sequence whenever for every $c \in \mathbb{E}$ with $\theta \ll c$ there is a natural number $n_{0}$ such that $d\left(x_{n}, x_{m}\right) \ll c$ for all $n, m \geq n_{0}$;

(iii) $(X, d)$ is complete cone $b$-metric if every Cauchy sequence in $X$ is convergent.

Remark 2.2 [17] The results concerning fixed points and other results, in case of cone spaces with non-normal solid cones, cannot be provided by reducing to metric spaces, because in this case neither of the conditions of Lemmas 1-4 in [10] hold. Further, the vector cone metric is not continuous in the general case, i.e., from $x_{n} \rightarrow x, y_{n} \rightarrow y$ it need not follow that $d\left(x_{n}, y_{n}\right) \rightarrow d(x, y)$.

Let $\mathbb{E}$ be an ordered Banach space with a positive cone $P$. The following properties hold $[17,19]$ :

(PT1) If $u \preceq v$ and $v \ll w$, then $u \ll w$.

(PT2) If $u \ll v$ and $v \preceq w$, then $u \ll w$.

(PT3) If $u \ll v$ and $v \ll w$, then $u \ll w$.

(PT4) If $\theta \preceq u \ll c$ for each $c \in \operatorname{int} P$, then $u=\theta$.

(PT5) If $a \preceq b+c$ for each $c \in \operatorname{int} P$, then $a \preceq b$.

(PT6) Let $\left\{a_{n}\right\}$ be a sequence in $\mathbb{E}$. If $c \in \operatorname{int} P$ and $a_{n} \rightarrow \theta$ (as $\left.n \rightarrow \infty\right)$, then there exists $n_{0} \in \mathbb{N}$ such that for all $n \geq n_{0}$, we have $a_{n} \ll c$.

\section{Main result}

According to [18], we denote by $\Lambda$ a family of nonempty closed and bounded subsets of $X$, and

$$
\begin{aligned}
& s(p)=\{q \in \mathbb{E}: p \preceq q\} \quad \text { for } q \in \mathbb{E}, \\
& s(a, B)=\bigcup_{b \in B} s(d(a, b))=\bigcup_{b \in B}\{x \in \mathbb{E}: d(a, b) \preceq x\} \quad \text { for } a \in X \text { and } B \in \Lambda .
\end{aligned}
$$

For $A, B \in \Lambda$, we define

$$
s(A, B)=\left(\bigcap_{a \in A} s(a, B)\right) \cap\left(\bigcap_{b \in B} s(b, A)\right) .
$$

Remark 3.1 Let $(X, d)$ be a cone $b$-metric space. If $\mathbb{E}=\mathbb{R}$ and $P=[0,+\infty)$, then $(X, d)$ is a $b$-metric space. Moreover, for $A, B \in C B(X), H(A, B)=\inf s(A, B)$ is the Hausdorff distance induced by $d$.

Now, we start with the main result of this paper.

Theorem 3.1 Let $(X, d)$ be a complete cone b-metric space with the coefficient $r \geq 1$ and cone $P$, and let $T: X \rightarrow \Lambda$ be a multivalued mapping. If there exists a function $\varphi: P \rightarrow\left[0, \frac{1}{r}\right)$ such that

$$
\lim _{n \rightarrow \infty} \sup \varphi\left(a_{n}\right)<\frac{1}{r}
$$


for any decreasing sequence $\left\{a_{n}\right\}$ in P. If for all $x, y \in X$,

$$
\varphi(d(x, y)) d(x, y) \in s(T x, T y)
$$

then $T$ has a fixed point in $X$.

Proof Let $x_{0}$ be an arbitrary point in $X$, then $T x_{0} \in \Lambda$, so $T x_{0} \neq \phi$. Let $x_{1} \in T x_{0}$ and consider

$$
\varphi\left(d\left(x_{0}, x_{1}\right)\right) d\left(x_{0}, x_{1}\right) \in s\left(T x_{0}, T x_{1}\right)
$$

By definition we have

$$
\varphi\left(d\left(x_{0}, x_{1}\right)\right) d\left(x_{0}, x_{1}\right) \in\left(\bigcap_{x \in T x_{0}} s\left(x, T x_{1}\right)\right) \cap\left(\bigcap_{y \in T x_{1}} s\left(y, T x_{0}\right)\right),
$$

which implies

$$
\varphi\left(d\left(x_{0}, x_{1}\right)\right) d\left(x_{0}, x_{1}\right) \in s\left(x, T x_{1}\right) \quad \text { for all } x \in T x_{0} .
$$

Since $x_{1} \in T x_{0}$, so we have

$$
\varphi\left(d\left(x_{0}, x_{1}\right)\right) d\left(x_{0}, x_{1}\right) \in s\left(x_{1}, T x_{1}\right) .
$$

We have

$$
\varphi\left(d\left(x_{0}, x_{1}\right)\right) d\left(x_{0}, x_{1}\right) \in \bigcup_{x \in T x_{1}} s\left(d\left(x_{1}, x\right)\right) .
$$

So there exists some $x_{2} \in T x_{1}$ such that

$$
\varphi\left(d\left(x_{0}, x_{1}\right)\right) d\left(x_{0}, x_{1}\right) \in s\left(d\left(x_{1}, x_{2}\right)\right) .
$$

It gives

$$
d\left(x_{1}, x_{2}\right) \preceq \varphi\left(d\left(x_{0}, x_{1}\right)\right) d\left(x_{0}, x_{1}\right) .
$$

By induction we can construct a sequence $\left\{x_{n}\right\}$ in $X$ such that

$$
d\left(x_{n}, x_{n+1}\right) \preceq \varphi\left(d\left(x_{n-1}, x_{n}\right)\right) d\left(x_{n-1}, x_{n}\right), \quad x_{n+1} \in T x_{n} \text { for } n \in \mathbb{N} .
$$

If $x_{n}=x_{n+1}$ for some $n \in \mathbb{N}$, then $T$ has a fixed point. Assume that $x_{n} \neq x_{n+1}$, then from (c) the sequence $\left\{d\left(x_{n}, x_{n+1}\right)\right\}$ is decreasing in $P$. Hence from (a) there exists $a \in\left(0, \frac{1}{r}\right)$ such that

$$
\lim _{n \rightarrow \infty} \sup \varphi\left(d\left(x_{n}, x_{n+1}\right)\right)<a
$$


Thus, for any $k \in\left(a, \frac{1}{r}\right)$, there exists some $n_{0} \in \mathbb{N}$ such that for all $n \geq n_{0}$, implies $\varphi\left(d\left(x_{n}, x_{n+1}\right)\right)<k$. Now consider, for all $n \geq n_{0}$,

$$
\begin{aligned}
d\left(x_{n}, x_{n+1}\right) & \preceq \varphi\left(d\left(x_{n-1}, x_{n}\right)\right) d\left(x_{n-1}, x_{n}\right) \prec k d\left(x_{n-1}, x_{n}\right) \prec k^{n-n_{0}} d\left(x_{n_{0}}, x_{n_{0}+1}\right) \\
& =k^{n} v_{0}
\end{aligned}
$$

where $v_{0}=k^{-n_{0}} d\left(x_{n_{0}}, x_{n_{0}+1}\right)$.

Let $m>n \geq n_{0}$. Applying (C3) to triples $\left\{x_{n}, x_{n+1}, x_{m}\right\},\left\{x_{n+1}, x_{n+2}, x_{m}\right\}, \ldots,\left\{x_{m-2}, x_{m-1}, x_{m}\right\}$, we obtain

$$
\begin{aligned}
d\left(x_{n}, x_{m}\right) & \preceq r\left[d\left(x_{n}, x_{n+1}\right)+d\left(x_{n+1}, x_{m}\right)\right] \\
& \preceq r d\left(x_{n}, x_{n+1}\right)+r^{2}\left[d\left(x_{n+1}, x_{n+2}\right)+d\left(x_{n+2}, x_{m}\right)\right] \\
& \preceq \cdots \\
& \preceq r d\left(x_{n}, x_{n+1}\right)+r^{2} d\left(x_{n+1}, x_{n+2}\right)+\cdots+r^{m-n-1}\left[d\left(x_{m-2}, x_{m-1}\right)+d\left(x_{m-1}, x_{m}\right)\right] \\
& \preceq r d\left(x_{n}, x_{n+1}\right)+r^{2} d\left(x_{n+1}, x_{n+2}\right)+\cdots+r^{m-n-1} d\left(x_{m-2}, x_{m-1}\right)+r^{m-n} d\left(x_{m-1}, x_{m}\right) .
\end{aligned}
$$

Now $d\left(x_{n}, x_{n+1}\right) \preceq k^{n} v_{0}$ and $k r<1$ imply that

$$
\begin{aligned}
d\left(x_{n}, x_{m}\right) & \preceq\left(r k^{n}+r^{2} k^{n+1}+\cdots+r^{m-n} k^{m-1}\right) v_{0} \\
& =r k^{n}\left(1+(r k)+\cdots+(r k)^{m-n-1}\right) v_{0} \\
& \preceq \frac{r k^{n}}{1-r k} v_{0} \rightarrow \theta \quad \text { when } n \rightarrow \infty .
\end{aligned}
$$

Now, according to (PT6) and (PT1), we obtain that for a given $\theta \ll c$ there exists $m_{0} \in \mathbb{N}$ such that

$$
d\left(x_{n}, x_{m}\right) \ll c \quad \text { for all } m, n>m_{0},
$$

that is, $\left\{x_{n}\right\}$ is Cauchy sequence in $(X, d)$. Since $(X, d)$ is a complete cone $b$-metric space, so there exists some $u \in X$ such that $x_{n} \rightarrow u$. Take $k_{0} \in \mathbb{N}$ such that $d\left(x_{n}, u\right) \ll \frac{c}{2 r}$ for all $n \geq k_{0}$. Now we will prove $u \in T u$. For this let us consider

$$
\varphi\left(d\left(x_{n}, u\right)\right) d\left(x_{n}, u\right) \in s\left(T x_{n}, T u\right)
$$

By definition we have

$$
\varphi\left(d\left(x_{n}, u\right)\right) d\left(x_{n}, u\right) \in\left(\bigcap_{x \in T x_{n}} s(x, T u)\right) \cap\left(\bigcap_{v \in T u} s\left(y, T x_{n}\right)\right),
$$

which implies

$$
\begin{aligned}
& \varphi\left(d\left(x_{n}, u\right)\right) d\left(x_{n}, u\right) \in\left(\bigcap_{x \in T x_{n}} s(x, T u)\right), \\
& \varphi\left(d\left(x_{n}, u\right)\right) d\left(x_{n}, u\right) \in s(x, T u) \quad \text { for all } x \in T x_{n} .
\end{aligned}
$$


Since $x_{n+1} \in T x_{n}$, so we have

$$
\varphi\left(d\left(x_{n}, u\right)\right) d\left(x_{n}, u\right) \in s\left(x_{n+1}, T u\right) .
$$

So there exists some $v_{n} \in T u$ such that

$$
\varphi\left(d\left(x_{n}, u\right)\right) d\left(x_{n}, u\right) \in s\left(d\left(x_{n+1}, v_{n}\right)\right) .
$$

It gives

$$
d\left(x_{n+1}, v_{n}\right) \preceq \varphi\left(d\left(x_{n}, u\right)\right) d\left(x_{n}, u\right) \preceq d\left(x_{n}, u\right) .
$$

Now consider

$$
\begin{aligned}
d\left(u, v_{n}\right) & \preceq r\left[d\left(u, x_{n+1}\right)+d\left(x_{n+1}, v_{n}\right)\right] \\
& \preceq r d\left(u, x_{n+1}\right)+r d\left(x_{n}, u\right) \\
& \ll \frac{c}{2}+\frac{c}{2}=c \quad \text { for all } n \geq k_{0},
\end{aligned}
$$

which means $v_{n} \rightarrow u$, since $T u$ is closed so $u \in T u$.

Corollary 3.1 [18] Let $(X, d)$ be a complete cone metric space with a normal cone $P$, and let $T: X \rightarrow C B(X)$ be a multivalued mapping. If there exists a function $\varphi: P \rightarrow[0,1)$ such that

$$
\lim _{n \rightarrow \infty} \sup \varphi\left(a_{n}\right)<1
$$

for any decreasing sequence $\left\{a_{n}\right\}$ in $P$. Iffor all $x, y \in X$,

$$
\varphi(d(x, y)) d(x, y) \in s(T x, T y)
$$

then $T$ has a fixed point in $X$.

Corollary 3.2 [15] Let $(X, d)$ be a complete metric space and let $T: X \rightarrow 2^{X}$ be a multivalued map such that $T x$ is a closed bounded subset of $X$ for all $x \in X$. If there exists a function $\varphi:(0, \infty) \rightarrow[0,1)$ such that $\limsup _{r \rightarrow t^{+}} \varphi(r)<1$ for all $t \in[0, \infty)$ and if

$$
H(T x, T y) \leq \varphi(d(x, y))(d(x, y)) \quad \text { for all } x, y \in X
$$

then $T$ has a fixed point in $X$.

The following is Nadler's theorem for multivalued mappings in a complete metric space.

Corollary 3.3 [14] Let $(X, d)$ be a complete metric space and let $T: X \rightarrow 2^{X}$ be a multivalued map such that $T x$ is a closed bounded subset of $X$ for all $x \in X$. If there exists $k \in[0,1)$ such that

$$
H(T x, T y) \leq k d(x, y) \quad \text { for all } x, y \in X,
$$

then $T$ has a fixed point in $X$. 
Example 3.1 Let $X=[0,1]$ and $\mathbb{E}$ be the set of all real-valued functions on $X$ which also have continuous derivatives on $X$. Then $\mathbb{E}$ is a vector space over $\mathbb{R}$ under the following operations:

$$
(x+y)(t)=x(t)+y(t), \quad(\alpha x)(t)=\alpha x(t)
$$

for all $x, y \in \mathbb{E}, \alpha \in \mathbb{R}$. That is, $E=C_{R}^{1}[0,1]$ with the norm $\|f\|=\|f\|_{\infty}+\left\|f^{\prime}\right\|_{\infty}$ and

$$
P=\{x \in \mathbb{E}: \theta \preceq x\}, \quad \text { where } \theta(t)=0 \text { for all } t \in X,
$$

then $P$ is a non-normal cone. Define $d: X \times X \rightarrow \mathbb{E}$ as follows:

$$
(d(x, y))(t)=|x-y|^{p} e^{t} \quad \text { for } p>1 .
$$

Then $(X, d)$ is a cone $b$-metric space but not a cone metric space. For $x, y, z \in X$, set $u=x-z$, $v=z-y$, so $x-y=u+v$. From the inequality

$$
(a+b)^{p} \leq(2 \max \{a, b\})^{p} \leq 2^{p}\left(a^{p}+b^{p}\right) \text { for all } a, b \geq 0,
$$

we have

$$
\begin{aligned}
& |x-y|^{p}=|u+v|^{p} \leq(|u|+|v|)^{p} \leq 2^{p}\left(|u|^{p}+|v|^{p}\right)=2^{p}\left(|x-z|^{p}+|z-y|^{p}\right), \\
& |x-y|^{p} e^{t} \leq 2^{p}\left(|x-z|^{p} e^{t}+|z-y|^{p} e^{t}\right),
\end{aligned}
$$

which implies that

$$
d(x, y) \preccurlyeq r[d(x, z)+d(y, z)] \quad \text { with } r=2^{p}>1 .
$$

But

$$
|x-y|^{p} e^{t} \leq|x-z|^{p} e^{t}+|z-y|^{p} e^{t}
$$

is impossible for all $x>z>y$. Indeed, taking advantage of the inequality

$$
(a+b)^{p}>a^{p}+b^{p}
$$

we have

$$
\begin{aligned}
& |x-y|^{p}>|x-z|^{p}+|z-y|^{p}, \\
& |x-y|^{p} e^{t}>|x-z|^{p} e^{t}+|z-y|^{p} e^{t}
\end{aligned}
$$

for all $x>z>y$. Thus the triangular inequality in a cone metric space is not satisfied, so $(X, d)$ is not a cone metric space but is a cone $b$-metric space.

Let $T: X \rightarrow \Lambda$ be such that

$$
T x=\left[0, \frac{x}{30}\right],
$$


then we have, for $x<y$,

$$
s(T x, T y)=s\left(\left|\frac{x}{30}-\frac{y}{30}\right|^{p} e^{t}\right) .
$$

Since

$$
\left|\frac{x}{30}-\frac{y}{30}\right|^{p} e^{t} \leq \frac{1}{3^{p}}|x-y|^{p} e^{t}
$$

so

$$
\frac{1}{3^{p}}\left(|x-y|^{p} e^{t}\right) \in s\left(\left|\frac{x}{30}-\frac{y}{30}\right|^{p} e^{t}\right) .
$$

Hence, for $\varphi(d(x, y))=\frac{1}{3^{p}}$, we have

$$
\varphi(d(x, y)) d(x, y) \in s(T x, T y)
$$

All conditions of our main theorems are satisfied, so $T$ has a fixed point.

\section{Competing interests}

The authors declare that they have no competing interests.

\section{Authors' contributions}

All authors contributed equally and significantly in writing this article. All authors read and approved the final manuscript.

\section{Author details}

'Department of Mathematics, COMSATS Institute of Information Technology, Chak Shahzad, Islamabad, 44000, Pakistan.

${ }^{2}$ Faculty of Mechanical Engineering, University of Belgrade, Kraljice Marije 16, Beograd, 11120, Serbia.

\section{Acknowledgements}

The authors thank the editors and the referees for their valuable comments and suggestions which improved greatly the quality of this paper.

Received: 16 August 2013 Accepted: 21 November 2013 Published: 12 Dec 2013

\section{References}

1. Banach, S: Sur les opérations dans les ensembles abstrait et leur application aux équations intégrales. Fundam. Math. 3, 133-181 (1922)

2. Arshad, M, Ahmad, J: On multivalued contractions in cone metric spaces with out normality. Sci. World J. 2013, Article ID 481601 (2013)

3. Azam, A, Arshad, M: Common fixed points of generalized contractive maps in cone metric spaces. Bull. Iran. Math Soc. 35(2), 255-264 (2009)

4. Azam, A, Arshad, M, Beg, I: Common fixed points of two maps in cone metric spaces. Rend. Circ. Mat. Palermo 57, 433-441 (2008)

5. Azam, A, Mehmood, N: Multivalued fixed point theorems in tvs-cone metric spaces. Fixed Point Theory Appl. 2013, 184 (2013). doi:10.1186/1687-1812-2013-184

6. Arshad, M, Azam, A, Vetro, P: Some common fixed point results in cone metric spaces. Fixed Point Theory Appl. 2009, Article ID 493965 (2009)

7. Boriceanu, M, Bota, M, Petrusel, A: Multivalued fractals in b-metric spaces. Cent. Eur. J. Math. 8(2), 367-377 (2010)

8. Czerwik, S: Nonlinear set-valued contraction mappings in b-metric spaces. Atti Semin. Mat. Fis. Univ. Modena 46, 263-276 (1998)

9. Deimling, K: Nonlinear Functional Analysis. Springer, Berlin (1985)

10. Huang, L-G, Zhang, X: Cone metric spaces and fixed point theorems of contractive mappings. J. Math. Anal. Appl. 332(2), 1468-1476 (2007)

11. Kutbi, MA, Ahmad, J, Azam, A: On fixed points of $\alpha$ - $\psi$-contractive multi-valued mappings in cone metric spaces. Abstr. Appl. Anal. 2013, Article ID 313782 (2013)

12. Kutbi, MA, Ahmad, J, Hussain, N, Arshad, M: Common fixed point results for mappings with rational expressions. Abstr. Appl. Anal. 2013, Article ID 549518 (2013)

13. Shatanawi, W, Rajić, VĆ, Radenović, S, Al-Rawashdeh, A: Mizoguchi-Takahashi-type theorems in tvs-cone metric spaces. Fixed Point Theory Appl. 2012, 106 (2012) 
14. Nadler, SB Jr.: Multi-valued contraction mappings. Pac. J. Math. 30, 475-478 (1969)

15. Mizoguchi, N, Takahashi, W: Fixed point theorems for multi-valued mappings on complete metric spaces. J. Math. Anal. Appl. 141, 177-188 (1989)

16. Rezapour, S, Hamlbarani, R: Some notes on the paper 'Cone metric spaces and fixed point theorems of contractive mappings'. J. Math. Anal. Appl. 345, 719-724 (2008)

17. Janković, S, Kadelburg, Z, Radenović, S: On cone metric spaces: a survey. Nonlinear Anal. 74, 2591-2601 (2011)

18. Cho, SH, Bae, JS: Fixed point theorems for multivalued maps in cone metric spaces. Fixed Point Theory Appl. 2011, 87 (2011)

19. Hussain, N, Shah, MH: KKM mappings in cone b-metric spaces. Comput. Math. Appl. 62, 1677-1684 (2011)

20. Huang, $\mathrm{H}, \mathrm{Xu}$, S: Fixed point theorems of contractive mappings in cone $b$-metric spaces and applications. Fixed Point Theory Appl. 2013, 112 (2013)

10.1186/1029-242X-2013-582

Cite this article as: Azam et al.: Multivalued fixed point theorems in cone $b$-metric spaces. Journal of Inequalities and Applications 2013, 2013:582

\section{Submit your manuscript to a SpringerOpen ${ }^{\ominus}$ journal and benefit from:}

- Convenient online submission

- Rigorous peer review

- Immediate publication on acceptance

- Open access: articles freely available online

- High visibility within the field

- Retaining the copyright to your article 